\title{
Antiangiogenic cancer treatment: The great discovery and greater complexity (Review)
}

\author{
EWA MAJ, DIANA PAPIERNIK and JOANNA WIETRZYK \\ Hirszfeld Institute of Immunology and Experimental Therapy, \\ Polish Academy of Sciences, 53-114 Wroclaw, Poland
}

Received July 5, 2016; Accepted September 8, 2016

DOI: 10.3892/ijo.2016.3709

\begin{abstract}
The discovery of tumor angiogenesis opened a new path in fighting cancer. The approval of different antiangiogenic agents, most targeting vascular endothelial growth factor (VEGF) signaling, has either increased the effectiveness of standard chemotherapy or even replaced it by offering better patient outcomes. However, an increasing number of preclinical and clinical observations have shown that the process of angiogenesis is far from clearly understood. Apart from targeting the VEGF pathway, novel strategies aim to influence other molecular factors that are involved in tumor angiogenesis. In addition, naturally occurring compounds seem to offer additional agents for influencing angiogenesis. The first concept of antiangiogenic therapy aimed to destroy tumor vessels, while it turned out that, paradoxically, antiangiogenic drugs normalized vasculature and as a result offered an improvement in chemotherapeutic delivery. In order to design an effective treatment schedule, methods for detecting the time window of normalization and biomarkers predicting patient response are needed. The initial idea that antiangiogenic therapy would be resistance-free failed to materialize and currently we still face the obstacle of resistance to antiangiogenic therapy.
\end{abstract}

\section{Contents}

1. Introduction

2. Treatment strategies

3. Vessel disruption or normalization

4. Toxicity

5. Predictive biomarkers

6. Resistance to antiangiogenic therapy

7. Conclusion

Correspondence to: Dr Ewa Maj, Hirszfeld Institute of Immunology and Experimental Therapy, Polish Academy of Sciences, R. Weigla 12, 53-114 Wroclaw, Poland

E-mail: ewa.maj@iitd.pan.wroc.pl

Key words: angiogenesis, bevacizumab, tyrosine kinase inhibitors, vascular endothelial growth factor, vessel normalization, time window

\section{Introduction}

The concept of antiangiogenic therapy in cancer patients started after observations performed by Judah Folkman approximately 45 years ago. He noticed that in order to grow beyond $1-2 \mathrm{~mm}^{3}$ tumors require blood supply and for that reason induce the generation of new vessels in the process of angiogenesis. Based on such observations, it was proposed that inhibition of tumor vessel formation could suppress tumor growth and that concept was called antiangiogenic therapy $(1,2)$. The next step in the field of discovering angiogenesis was the isolation and characterization of the vascular endothelial growth factor (VEGF), initially termed the vascular permeability factor (VPF) by Senger et al (3) and Ferrara (4). VEGF is the best characterized angiogenic factor. The function of VEGF is to modulate vessel permeability, remodeling, endothelial cell (EC) survival, proliferation and migration $(5,6)$. VEGF is overexpressed in cancer cells $(7,8)$. Very high levels of VEGF and other proangiogenic factors result in the formation of new vessels, but their architecture and function is abnormal. Tumor vessels are dilated, tortuous, and disorganized with haphazard patterns (lack microvascular hierarchy) and their pore sizes are 100 times bigger than is physiologically normal. ECs forming tumor vessels are loosely connected with each other and have an irregular morphology. Perivascular cells, i.e. pericytes and vascular smooth muscle cells that normally stabilize blood vessels by covering ECs, within tumors are absent or poorly attached to vessels. The vascular basement membrane is also abnormal: thick in some tumors or thin or even absent in others. These structural abnormalities cause functional aberrations. Tumor vessels are hyperpermeable and hence intravascular fluid and plasma proteins extravasate, causing an increase in interstitial fluid pressure (IFP). The blood supply is heterogeneous, some areas are hyper- whilst other are hypovascularized. As a consequence, hypoxia and acidosis occur within a tumor. Moreover, hypoxia is one of the mechanisms regulating VEGF expression; therefore, the formation of abnormal vasculature intensifies in a self-reinforcing vicious cycle. The chronic imbalance of the pro- and anti-angiogenic factors in cancer, i.e. excess of pro- and deficiency of antiangiogenic factors, leads to abnormal angiogenesis $(9,10)$. Thus, VEGF, as a main agent involved in angiogenesis and signaling pathway engaged in the regulation of the function of ECs, became a target in developing antiangiogenic therapies (11). 


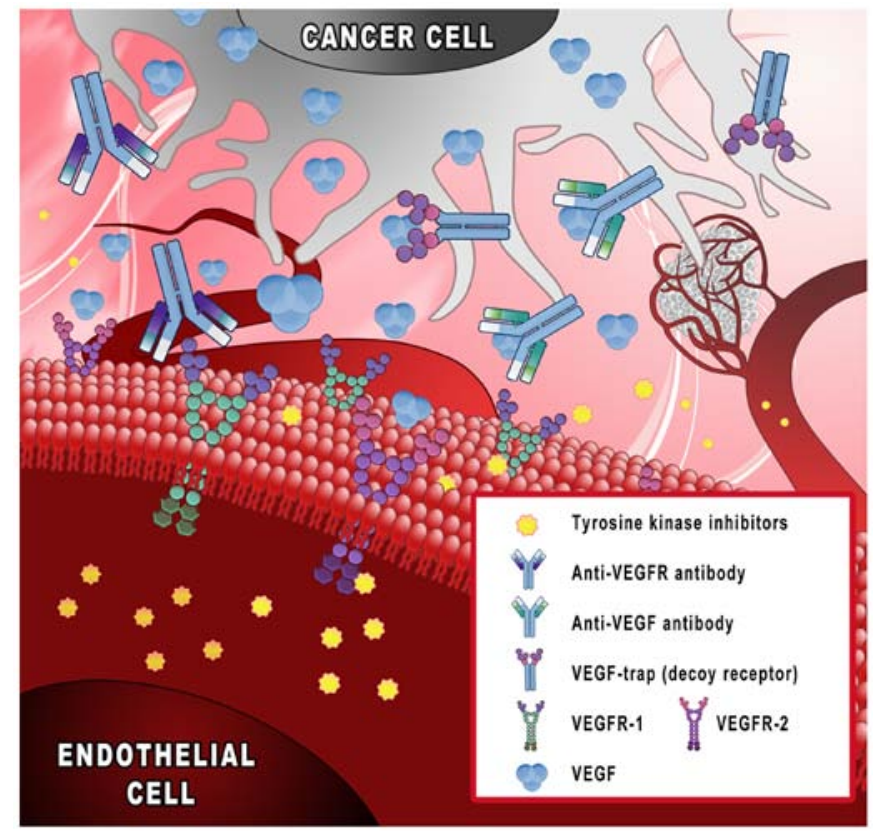

Figure 1. Antiangiogenic strategies in cancer therapy. VEGF/VEGFR axis is the main proangiogenic signaling pathway. In many cancer types VEGF is overexpressed, what in turn results in tumor neoangiogenesis. There are four main approaches aiming to inhibit VEGF signaling in cancer: smal molecule tyrosine kinase inhibitors (TKI), that block tyrosine kinase activity of VEGFR, neutralizing monoclonal antibodies that bind circulating VEGF, monoclonal antibodies targeting VEGFR and recombinant protein, so called 'decoy receptor' or 'VEGF-trap' that bind more than one proangiogenic growth factor.

In this report we discuss current issues related to the field of antiangiogenic therapy: treatment strategies, vessel normalization, toxicity, predictive biomarkers and resistance to antiangiogenic therapy.

\section{Treatment strategies}

FDA approved antiangiogenic drugs. Currently, there are few main approaches in targeting angiogenesis which have been tested in clinical trials and approved in clinical practice (Fig. 1): i) monoclonal antibodies binding VEGF (bevacizumab); ii) decoy receptors, 'VEGF-trap' (aflibercept); iii) tyrosine kinase inhibitors (sunitinib and sorafenib); and iv) monoclonal antibodies targeting VEGF receptors (ramucirumab) (11-13).

These agents are being used in the treatment of different cancer types: breast, colorectal, hepatocellular, gastric, lung and others (14). One of the first approaches in antiangiogenic therapy was the monoclonal antibody neutralizing circulating VEGF. In 2004, the first phase III trial results showed that bevacizumab, a humanized monoclonal antibody binding specifically to VEGF-A alone, when combined with chemotherapy in metastatic colorectal cancer improved progression-free survival PFS (10.6 vs. 6.2 months) and overall survival OS (23 vs. 15.3 months) compared to chemotherapy arm (15). An improvement in PFS for the combination of bevacizumab plus chemotherapy was next shown in two phase III trials in non-squamous non-small cell lung cancer (NSCLC) (16-18), but only one study reported an improvement in OS (16). Within the next few years, bevacizumab was approved as a monotherapy in second line treatment of glioblastoma and in combined treatment with interferon $\alpha$ for renal cell carcinoma. There were some controversies in cases of using bevacizumab in the treatment of metastatic breast cancer. The ECOD 2100 trial showed that adding bevacizumab to paclitaxel improved PFS (11.8 vs. 5.9), as well as OS rates (36.9 vs. $21.2 \%$ ) compared to paclitaxel alone. Based on those results, the US Food and Drug Administration (FDA) accelerated in 2008 approval of bevacizumab in combination with paclitaxel in metastatic breast cancer. Further trials, AVADO and RIBBON-1, confirmed the improvement of PFS by bevacizumab, but neither demonstrated any improvement of OS. In 2011, FDA withdrew approval for bevacizumab in metastatic breast cancer (19). In 2014, bevacizumab was approved for the treatment of patients with platinum-resistant recurrent epithelial ovarian, fallopian tube, or primary peritoneal cancer in combination with paclitaxel, pegylated liposomal doxorubicin or topotecan, based on the results of AURELIA clinical trials comparing bevacizumab plus chemotherapy with chemotherapy alone $(20,21)$. Also in 2014, bevacizumab was approved in combination with paclitaxel and cisplatin or paclitaxel and topotecan in persistent, recurrent or metastatic cervical cancer $(22,23)$.

Tyrosine kinase inhibitors (TKIs) are small-molecularweight drugs that inhibit the kinase activity of different receptors. The mechanism of action of TKIs relies on binding around the ATP binding site of a given receptor and thus hindering phosphorylation of the tyrosine residue of that receptor and subsequent transmission of signaling down the intercellular pathway (2). There are 28 small-molecule kinase inhibitors (tyrosine kinase, serine/threonine kinase or dual protein kinase inhibitors) approved by the FDA. Among these, there are some agents that target VEGF receptors (VEGFR) and these are used to treat different types of cancer, e.g. sunitinib, sorafenib, axitinib and pazopanib (Table I) $(24,25)$. Compared to VEGF neutralizing antibodies, TKI do not interfere with the binding of VEGF to its receptors and they usually target not only VEGFR but additionally other kinases, such as PDGFR, FGFR and c-KIT (9).

Another strategy developed to inhibit angiogenesis is a human recombinant fusion protein called aflibercept, acting as a decoy receptor of angiogenic factors. Aflibercept, unlike bevacizumab, targets not only VEGF-A, but also VEGF-B and placental growth factor (PlGF). This is a fusion protein of the 2nd immunoglobulin domain of VEGFR1, 3rd immunoglobulin domain of VEGFR2 and constant region Fc of human IgG1. In 2012, FDA approved aflibercept in the treatment of metastatic colorectal cancer (CRC) with infusional fluorouracil, leucovorin and irinotecan, based on phase III trial results (26).

Ramucirumab is another human monoclonal antibody developed to inhibit angiogenesis. It blocks the interaction of VEGF with its receptor by binding to the extracellular domain of VEGFR2. Preclinical studies showed that ramucirumab binds selectively to VEGFR2 with a greater efficacy than its natural ligand VEGF-A. It is approved in second line treatment in gastric, NSCLC and colon cancer. Based on the RAISE study, ramucirumab was approved in combination with FOLFIRI (folinic acid, 5-fluorouracil and irinotecan) in metastatic CRC patients, if disease progressed after therapy with bevacizumab, oxaliplatin and fluoropirymidine. In NSCLC, 
Table I. FDA approved tyrosine kinase inhibitors with known anti-VEGFR activity.

\begin{tabular}{|c|c|c|c|}
\hline TKI & Activity & $\begin{array}{l}\text { Initial US } \\
\text { approval }\end{array}$ & Indications $^{\mathrm{a}}$ \\
\hline Axitinib & VEGFR 1-3 & 2012 & Advanced RCC \\
\hline Cabozantinib & $\begin{array}{l}\text { RET, MET, VEGFR 1-3, } \\
\text { KIT, TRKB, FLT-3, AXL, TIE-2 }\end{array}$ & 2012 & Progressive, metastatic medullary thyroid cancer \\
\hline Lenvatinib & $\begin{array}{l}\text { VEGFR 1-3, FGFR 1-3, PDGFR } \alpha \text {, } \\
\text { KIT, RET }\end{array}$ & 2015 & $\begin{array}{l}\text { Locally recurrent or metastatic, progressive, } \\
\text { radioactive iodine-refractory thyroid cancer }\end{array}$ \\
\hline Nintedanib & FGFR 1 -3, PDGFR $\alpha / \beta$, VEGFR 1-3, FLT3 & 2014 & Idiopatic pulmonary fibrosis \\
\hline Pazopanib & $\begin{array}{l}\text { VEGFR 1-3, PDGFR } \alpha / \beta \text {, FGFR } 1 / 3, \text { KIT, } \\
\text { LCK, FMS, Itk }\end{array}$ & 2009 & Advanced RCC, advanced soft tissue carcinoma \\
\hline Ponatinib & $\begin{array}{l}\text { BCR-ABL, BCR-ABL T315I, VEGFR, } \\
\text { PDGFR, FGFR, EPHR, SRC family } \\
\text { kinases, KIT, RET, TIE2, FLT3 }\end{array}$ & 2012 & $\begin{array}{l}\text { Adult patients with } \mathrm{T} 3151^{+} \mathrm{CML} \text { (chronic phase, } \\
\text { accelerated phase, or blast phase) or } \mathrm{T} 3151^{+} \mathrm{Ph}^{+} \\
\text {ALL; adult patients with chronic phase, accelerated } \\
\text { phase, or blast phase CML or } \mathrm{Ph}^{+} \mathrm{ALL} \text { for whom } \\
\text { no other tyrosine kinase inhibitor (TKI) therapy } \\
\text { is indicated }\end{array}$ \\
\hline Regorafenib & $\begin{array}{l}\text { VEGFR 1-3, BCR-ABL, B-RAF, } \\
\text { B-RAF(V600E), KIT, PDGFR } \alpha / \beta, \\
\text { RET, FGFR1/2, TIE2, Eph2A }\end{array}$ & 2012 & $\begin{array}{l}\text { Metastatic CRC treated previously with fluoropyri- } \\
\text { midine, oxaliplatin and irinotecan; locally advanced, } \\
\text { unresectable or metastatic GIST treated previously } \\
\text { with imatinib or sunitinib }\end{array}$ \\
\hline Sorafenib & $\begin{array}{l}\text { B/C-RAF, B-RAF(V600E), KIT, FLT3, } \\
\text { RET, VEGFR 1-3, PDGFR } \beta\end{array}$ & 2005 & $\begin{array}{l}\text { Unresectable hepatocellular carcinoma, advanced } \\
\text { RCC, locally recurrent or metastatic, progressive, } \\
\text { differentiated TC refractory to radioactive iodine } \\
\text { treatment }\end{array}$ \\
\hline Sunitinib & $\begin{array}{l}\text { PDGFR } \alpha / \beta \text {, VEGFR 1-3, KIT, FLT3, } \\
\text { CSF-1R, RET }\end{array}$ & 2006 & $\begin{array}{l}\text { GIST after disease progression on or intolerance to } \\
\text { imatinib mesylate, advanced RCC, progressive, } \\
\text { well-differentiated pNET }\end{array}$ \\
\hline Vandetanib & $\begin{array}{l}\text { EGFRs, VEGFRs, RET, BRK, TIE2, } \\
\text { EPHRs, SRC family kinases }\end{array}$ & 2011 & Symptomatic or progressive medullary TC \\
\hline
\end{tabular}

${ }^{\text {aD }}$ ata collected from FDA website (29). RCC, renal cell carcinoma; CML, chronic myeloid leukemia; ALL, acute lymphoblastic leukemia; $\mathrm{Ph}^{+}$, Philadelphia chromosome positive; CRC, colorectal carcinoma; GIST, gastrointestinal stromal tumor; TC, thyroid cancer; pNET, pancreatic neuroendocrine tumor.

ramucirumab was approved in combination with docetaxel after platinum-based chemotherapy. In gastric cancer patients, FDA approved ramucirumab as a monotherapy in advanced or metastatic disease or in gastroesophageal junction carcinoma patients for whom 1st line chemotherapy had failed $(27,28)$.

Other strategies in preclinical and clinical studies. Apart from the above already approved antiangiogenic agents, additional strategies have been developed aimed at inhibiting tumor angiogenesis, directly or indirectly, that are being tested in preclinical and clinical trials. These include agents that target angiogenesis directly: PlGF, angiopoietin-Tie2 axis, integrins or agents targeting angiogenesis indirectly by inhibiting oncogenic pathways (e.g. HER2, PI3K/AKT/mTOR and mutated EGFR) or hormone signaling (9). Moreover, some known anticancer drugs designed for specified mechanisms of action may reveal previously unknown antiangiogenic activity, due to interaction with other signaling pathways that had not initially been considered. For example, Calero et al (30) showed that sunitinib, TKI designed to inhibit VEGF receptor activity, decreased VEGF secretion from SK-N-BE(2) neuroblastoma cells. The lowered VEGF expression correlated with both PI3K/AKT signaling pathway inhibition after sunitinib treatment and increased MYC protein degradation. In turn, in a lung cancer model, treatment with imatinib resulted in downregulation of VEGF expression in A549 tumors, which was accompanied by upregulation of p53 expression (31). Legros et al (32) showed that imatinib administration in CML patients resulted in a decrease in plasma VEGF level and in VEGF secretion in cultured K562 cells as a consequence of MAPK and PI3K pathway inhibition and VEGF promoter transcriptional activity inhibition. It was also surprising that some cytotoxic agents cause 'antiangiogenic side-effects', when applied in low, metronomic doses given more frequently, e.g. weekly or even daily, and this was more effective in tumor growth inhibition than the commonly used maximum 
tolerated dose (MTD) schedule (33-35). Given in a metronomic schedule, docetaxel downregulated VEGF expression in gastric cancer BGC-823 cells and VEGF, bFGF, matrix metalloproteinase (MMP)-2 and MMP-9 in colon adenocarcinoma LS174T cells, while it upregulated TSP-1 expression in HUVEC cells and decreased microvessel density (MVD) and VEGF and increased TSP-1 in tumor tissue of a BGC-823 model $(36,37)$.

Another concept in anticancer treatment related to angiogenesis is the inhibition of metastatic potential through an influence on the interaction between cancer cells and ECs and platelets with compounds targeting cyclooxygenase-2/prostacyclin pathways. The use of 1,4-dimethylpyridinium chloride (1,4-DMP) has been shown to decrease the number of metastases in combination with cyclophosphamide in a 4T1 breast cancer model (38).

There are also some interesting studies on the anticancer activity of naturally occurring products and their potential usefulness as chemopreventive agents. These are also being tested for their antiangiogenic activity. The antiangiogenic effect of plant extracted compounds involves: EC proliferation and migration inhibition, preventing sprout formation, MMP inhibition and modulation of angiogenic signaling pathways. Plant-based agents demonstrate synergism when used in combination with chemotherapy and many of them reveal low levels of undesired side-effects, or even limit side-effects caused by chemotherapy $(14,39,40)$. These agents have also been tested in the context of ocular diseases, where excessive ocular neoangiogenesis is, like cancer neovascularization, the consequence of an imbalance between pro- and antiangiogenic factors. It has been shown that different natural compounds, e.g. curcumin, genistein, luteolin and resveratrol, suppress retinal neovascularization in different in vitro and in vivo models (41). One of the plant-derived compounds extensively studied for anticancer and antiangiogenic activity is soy isoflavon genistein, first isolated in 1899. The antiangiogenic activity of genistein was revealed as the ability to decrease microvessel density, lower VEGF and increase endostatin plasma level $(42,43)$. However, the exact results of genistein treatment depend on the doses used: at high and medium concentrations of soy isoflavones $(10-150 \mu \mathrm{M})$ antiangiogenic activity has been observed, while at lower doses $(<10 \mu \mathrm{M})$ genistein tended to increase VEGF secretion from breast cancer cells (44). The antiangiogenic properties of genistein have also shown its ability to prevent metastasis or lower blood supply measured in Lewis lung cancer and B16 melanoma models (45-47). Another natural agent generating general interest in anticancer research is resveratrol, a phytochemical of grapes, berries and peanuts. On human ovarian cancer cells it has been shown that resveratrol attenuates the induction of HIF-1 $\alpha$ and VEGF by lipopolysaccharide LPS $(42,48)$. Resveratrol also inhibits mediation of tumor necrosis factor $\alpha$ (TNF $\alpha$ ) MMP-9 expression in HepG2 hepatocellular carcinoma cells and also NF- $\kappa$ B expression and invasion of HepG2 cells (49). The identified mechanisms of antiangiogenic activity of natural, plant derived agents so far include: interfering with signaling of VEGF and FGF, decreased vascular permeability by inhibiting NO release from ECs, modulation of NF- $\mathrm{KB}$ activity, and inhibition of HIF-1 $\alpha$ expression and its downstream targets (VEGF, TNF $\alpha$, COX2, IL-6 and IL-8) (41).
Another important naturally occurring compound that is intensively studied in cancer research is vitamin $\mathrm{D}$, a steroid hormone regulating calcium and phosphate homeostasis (50). Vitamin D is synthesized in the skin upon UVB exposure from 7-dehydrocholesterol and next hydroxylated at C-25 and $\mathrm{C}-1$ in the liver and kidney, respectively. Vitamin D can also be obtained from the diet, especially from food of animal origin, fish, meat, eggs and milk products, but it has also been shown that vitamin D can be found in plants (51). Calcitriol, the active form of vitamin $D_{3}$, regulates many cellular and tissue processes involved in carcinogenesis: proliferation, differentiation, apoptosis, inflammation, invasiveness and metastasis by transcriptional regulation of gene expression (genomic action) or by influencing different signaling pathways (rapid, non-genomic action) $(50,52,53)$. One of the first pieces of evidence for the antiangiogenic activity of calcitriol was a study on 4.5-day old chick embryos, where it was shown that calcitriol and vitamin $\mathrm{D}_{3}$ analog, 22-oxa-1 $\alpha, 25$-dihydroxyvitamin $\mathrm{D}_{3}$, inhibited angiogenesis in chorioallantoic membranes (54). Calcitriol reduces the expression of proangiogenic factors, e.g. VEGF, and IL-8, and inhibits the proliferation of ECs derived from tumors through the induction cell cycle arrest and apoptosis (55-57). In azoxymethane-induced colon cancer in rats, vitamin D derivative administration resulted in decreased immunohistochemical staining of VEGF and microvessel counts (58). In LLC cells, vitamin D derivatives reduced MMP-2, MMP-9 and VEGF expression and in in vivo Matrigel assays inhibited angiogenesis induced by bFGF (59). In another study using the LLC model, it was shown that calcitriol and its analog PRI-2191 inhibit growth and metastasis of LLC cells transplanted subcutaneously. Moreover, a tendency to decrease blood vessel diameter, without influencing their number, was observed. This observation may suggest the influence of calcitriol and its analog on tumor growth not only directly, but also through normalization of tumor vasculature (60). Therefore, a number of in vitro and in vivo studies have proved that vitamin $\mathrm{D}$ has a significant impact on the process of angiogenesis (50). Unfortunately, the biological anticancer activity of calcitriol can only be obtained when administered in high doses, which limits its use due to the risk of hypercalcemia. This has inspired many scientists to synthesize vitamin $\mathrm{D}$ analogs in order to dissociate calcemic from antiproliferative activity of vitamin $\mathrm{D}$. These analogs were then tested alone or in combinations in cancer research $(53,61-63)$. No vitamin D compounds are currently used in clinical practice for cancer treatment, although in preclinical animal cancer models several vitamin D analogs have appeared to be potent drugs, especially in combination with known chemotherapy $(31,63-66)$. To date, a small number of studies have assessed the influence of vitamin D and its derivatives on angiogenesis (63). In clinical trials, vitamin D supplementation has been studied with the aim of reducing the risk of cancer. In addition, vitamin $\mathrm{D}$ has been studied in combination with chemotherapy, mainly in prostate cancer patients. However, results are still inconsistent and no clear conclusions have been made in this field; therefore, more studies are required (67-71).

The uncovered anticancer and antiangiogenic activity of many natural compounds may offer a great opportunity 
A Normal vessels
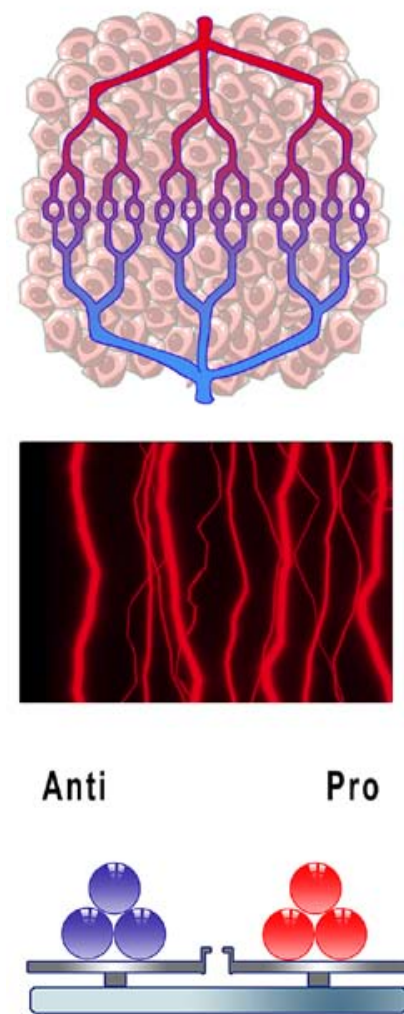

B Abnormal vessels
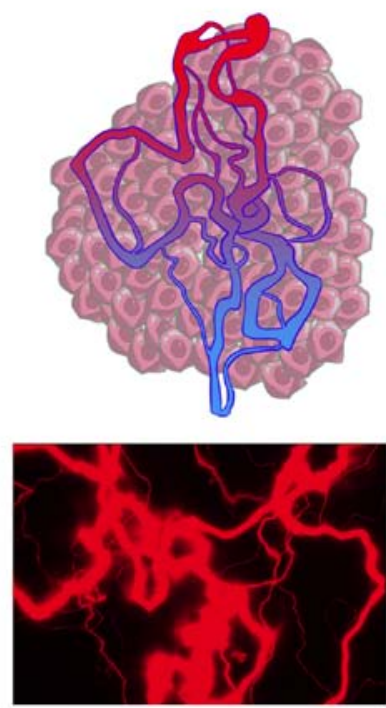

Anti

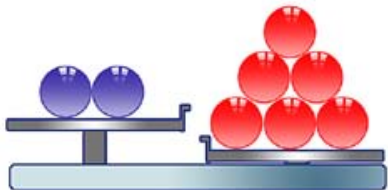

C Normalized vessels
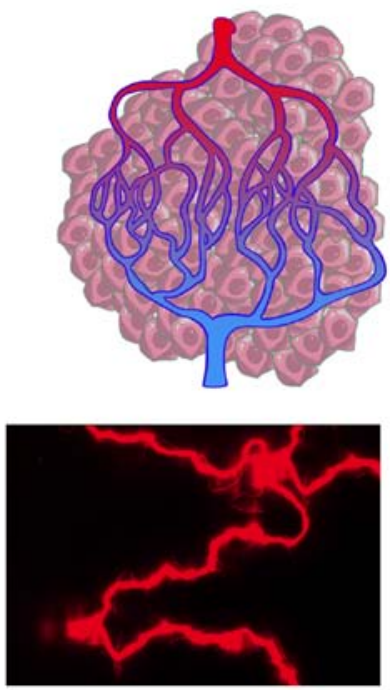

Anti Pro

Figure 2. Hypothesis of tumor vessel normalization. (A) Angiogenesis in healthy tissues is regulated by the equilibrium of anti- and proangiogenic factors. (B) In tumors the balance is moved to the advantage of proangiogenic factors due to overexpression of proangiogenic factors in different cells including cancer cells, what results in abnormal structure and function of blood vessels and leads to hypoxia. (C) The inhibition of elevated level and signaling pathways of proangiogenic factors reverts the balance of angiogenic factors and normalizes the vasculature.

in cancer prevention or may strengthen existing anticancer treatment options. It is believed that the use of such natural health products may be beneficial, as they may act through many signaling pathways and reduce the development of resistance by cancer cells and therefore improve patient outcomes $(39,40,42)$.

\section{Vessel disruption or normalization}

The rationale behind antiangiogenic therapy was the concept that blocking blood vessel formation in tumors or its regression would deprive cancer cells of nutrients and oxygen and finally starve tumors to death or induce tumor dormancy. One of the first preclinical studies clearly showed that treatment with an anti-VEGF monoclonal antibody caused a significant vascular density reduction and tumor growth delay in mice bearing xenografts of glioblastoma multiforme, leiomyosarcoma and rhabdomyosarcoma (72). It turned out, however, that antiVEGF monotherapy in clinical trials of human solid tumors showed only modest objective response rates and lacked noticeable survival benefits for patients (73). After many years of clinical trials, anti-VEGF agents appeared to be active as single agents only in a limited number of cancers, e.g. renal cell carcinoma, hepatocellular carcinoma, ovarian, neuroendocrine tumors and glioblastoma. In contrast, in other studied cancers, CRC, NSCLC and breast cancer, the administration of anti-VEGF drugs was effective only when combined with chemotherapy, leading to significant improvements of PFS and OS compared to chemotherapy alone $(73,74)$.

Such clinical results thus generated some confusion. It is known that the efficacy of chemotherapy depends on efficient delivery of cytotoxic agents to tumor cells through efficient blood flow, whilst antiangiogenic therapy, according to the theory, should destroy blood vessels and thus prevent drug delivery. In order to elucidate these seemingly counterintuitive observations the hypothesis of 'vessel normalization' was proposed in 2001, that is many years after the importance of inhibiting tumor angiogenesis had been identified (10). It was assumed that judicious administration of antiangiogenic drugs reverts the abnormal structure and function of the tumor vessels towards normal state (Fig. 2). In this regard, treatment with antiangiogenic agents would correct the arrangement of vasculature towards a more organized structure leading to increased homogeneity in blood flow. Furthermore, improvement in junctions between ECs, increases in pericyte content around vessels and also better connections between ECs and pericytes would decrease vascular permeability with a simultaneous decline in intratumoral fluid pressure. As a result, cytotoxic drugs would be effectively delivered to cancer cells owing to increased and efficient blood perfusion within the tumor $(75,76)$. Indeed, many preclinical and clinical studies have shown that antiangiogenic therapy results in vascular normalization. For example, it has been shown in preclinical studies with different human tumors that administration of 
an anti-VEGF A4.6.1 antibody results in a reduction in vessel diameter and tortuosity, a significant decline in vascular permeability to plasma proteins, providing evidence that after neutralizing tumor cell-derived VEGF abnormalities of tumor vasculature could be reversed (77). Similar results have been achieved in studies with the use of bevacizumab in combination with chemotherapy or ionizing radiation. After bevacizumab administration of mice bearing neuroblastoma or rhabdomyosarcoma xenografts, a substantial decrease in tumor microvessel density and improved pericyte coverage in tumors has been observed with a concomitant decrease in vascular permeability, a drop in intratumoral fluid pressure and an increase in intratumoral oxygen pressure $(78,79)$. Tumor vessel normalization could also be observed after using tyrosine kinase inhibitors. In a murine Lewis lung cancer model, treatment with axitinib resulted in reduction in microvessel density and vascular sprouting (80). Similarly, the administration of sunitinib in a human glioma model resulted in a decrease in MVD and collagen IV density (but no effect on $\alpha$-SMA density) and an improvement in tamizolomide penetration into brain tumors $(81,82)$. Some clinical studies have also demonstrated the occurrence of vascular normalization in cancer patients after treatment with antiangiogenic agents. A study in patients with locally advanced rectal adenocarcinoma receiving bevacizumab 7 weeks before surgical resection, first dose was given alone and after 2 weeks with 5-fluorouracil, showed a decline in tumor microvessel density, a reduction of intratumoral fluid pressure, and an increase in the content of pericytes covering vessels (83). More examples of vessel normalization as a consequence of antiangiogenic therapy have been reviewed elsewhere (9).

Hypoxia induced by abnormal tumor vascularity influences the immune response in cancer. This contributes to immune tolerance by inhibiting the proliferation and activity of $\mathrm{T}$ lymphocytes and inducing accumulation and polarization of immune cells towards suppressive phenotypes. It has been proposed that normalizing tumor vascularity could enhance the adoptive cell transfer efficacy (84). In 2012, Huang et al (85) demonstrated that antiangiogenic treatment influences the effectiveness of immunotherapy by the modulatory activity of antiangiogenic agents on tumor microenvironment. In a breast cancer model, the authors studied the influence of administration of anti-VEGFR2 antibody on anticancer vaccine therapy in immune-tolerant and immunogenic mice. The study showed that treatment with an anti-VEGFR2 antibody enhanced anticancer activity of whole cancer cell vaccine in a $\mathrm{CD}^{+}$ T-cell-dependent manner in both murine models. Additionally, the efficacy of the tested therapy depended on the dose of the anti-VEGF agent: lower doses of anti-angiogenic agent were superior to higher doses in augmenting the infiltration of tumor with $\mathrm{CD}^{+}$and $\mathrm{CD}^{+}$T-cells and in polarizing tumor-associated macrophages, from immunosuppressive M2 towards immunostimulatory M1 phenotypes.

Data obtained in preclinical and clinical studies have shown that after cessation of the antiangiogenic therapy rapid revascularization occurs in tumors, which can be followed by rapid regrowth of the tumor (86-88). It turned out that vessel normalization obtained as a result of antiangiogenic therapy is transient. The period when the vessel normalization is present is called the 'time window' or 'window of opportunity'. The temporariness of normal features of tumor vessels may result from discontinuation of therapy or rest periods in therapy schedules, but also as a consequence of excessive doses or prolonged administration of antiangiogenic drugs $(9,89)$. Studies have shown that abnormalities of tumor vessels are reversed as early as 24-72 $\mathrm{h}$ after starting the therapy and are sustained for different periods, from few to dozen days, or sometimes longer $(78,90,91)$. The existence of a time window is important for appropriate scheduling of combined treatment. Many studies have shown that the efficacy of combined antiangiogenic and chemotherapy treatment is schedule-dependent. Since successful activity of cytotoxic drugs depends on efficient drug delivery to cancer cells, which can be obtained after vessel normalization, it has been proposed that chemotherapy or radiotherapy should be applied after administration of antiangiogenic agents $(78,92,93)$. In a study of 2 patients with metastatic breast cancer, Chen et al (89)analyzed the time of appearance of vessel normalization after bevacizumab administration by means of three-dimension power Doppler ultrasonography and observed that the window was open 20-24 h after bevacizumab injection. Additionally, it was shown that sequential treatment of bevacizumab: on days 1 and 15, and paclitaxel: on days 2, 9 and 16 resulted in rapid reduction of tumors in brain, as observed in computed tomography.

The optimal timing of administration of anti-VEGF agents before cytotoxic agents is required to achieve the highest anticancer response of treatment used. The challenge is the method of determination of the normalization window in a patient, and what is more non-invasively. There have been some studies aimed at probing the time window of vessel normalization. Vangestel et al (94) used ${ }^{99 \mathrm{~m}}$ Tc-tricarbonyl His-annexin A5, radiotracer of apoptosis to explore the timing between administration of bevacizumab and irinotecan in a colon cancer model that would result in the greatest tumor cell death. HernandezAgudo et al (95) used ${ }^{18} \mathrm{~F}$-misonidazole ((18F)-FMISO) PET as a hypoxia tracer in order to explore vessel normalization after administration of divotinib in pancreas and breast cancer models. After a decrease in hypoxia, and therefore vessel normalization, the delivery of chemotherapy was improved and so was the cytotoxic effect. Data obtained in that study suggested that (18F)-FMISO mirrors the dynamic of hypoxia and changes in vessel normality/abnormality in response to a short course of antiangiogenic therapy. Other candidate biomarkers tested to assess the response to anti-VEGF therapy are: tumor biopsy, measuring plasma protein concentration e.g. VEGF, or level of circulating ECs and progenitor cells, also imaging diagnostic methods (CT, PET, MRI) (73).

\section{Toxicity}

As angiogenesis in adults is a rather rare process, it was thought that anti-VEGF therapies would be free of toxicity. However, clinical practice showed that anti-angiogenic therapy is accompanied with a number of side-effects, including hemorrhage, hypertension, proteinuria, impaired wound healing, thrombosis and others (11). Preclinical studies with non-tumor bearing mice administered with anti-angiogenic agents have shown that the treatment alters the density and architecture of vessels in multiple tissues and organs, especially in endocrine organs that had fenestrated vessels as a result of antiangiogenic therapy (96). 
Yang et al (97) showed that systemic administration of antiVEGF and anti-VEGFR neutralizing antibodies affected the vasculature of multiple organs, with the greatest vessel regression in endocrine glands, intestine and uterus. On the other hand, high levels of VEGF produced by cancer cells correlated with abnormal hepatic sinusoidal blood vessels and high mortality in a VEGF expressing melanoma model (98). Cancer patients, mostly in the advanced stage of the disease, experience so-called cancer-associated systemic syndrome (CASS) or paraneoplastic syndrome as a result of production and secretion excess amounts of different peptides and hormones that affect diverse systems, most frequently the endocrine, gastrointestinal, neurologic, dermatologic and hematologic systems. Physiologically, these factors are paracrine hormones, but when overproduced by malignant cells they enter the circulation and influence distant tissues and organs deregulating homeostasis $(96,99,100)$. Elevated levels of VEGF expressed by cancer cells induced CASS in mice, manifesting with severe anemia, ascites, hepatic dysfunction, and decreases in serum corticosterone levels, whilst the use of anti-VEGF agents resulted in vessel normalization in healthy tissues and improved survival of animals $(98,100)$. These surprising observations show that antiangiogenic therapy may also have an impact on improving healthy tissue and organ function in cancer patients.

\section{Predictive biomarkers}

Efforts are being made to identify some biomarkers that could predict the clinical benefits of antiangiogenic therapy for a given patient. Since the monoclonal antibody bevacizumab specifically targets VEGF, it was assumed that measuring serum VEGF levels could serve as a predictive marker for patient selection. Unfortunately, so far it has not been proved that VEGF level, in blood or in tumor biopsies, could fulfill the requirements of a predictive biomarker $(101,102)$. Studies on circulating VEGF levels in cancer patients have shown the importance of VEGF as a prognostic rather than predictive biomarker (11). On the other hand, it has turned out that some of the adverse effects related to antiangiogenic agents appeared to be positively correlated with response to therapy. For example, it was shown that hypertension associated with the bevacizumab or TKIs correlated with clinical response in patients with breast, colorectal and NSCLC, whilst skin rashes correlated with drug response in patients with colorectal and hepatocellular carcinoma (96). Another approach in predicting the response to antiangiogenic therapy was the imaging of tumor vasculature, with the use of CT, MRI or PET. In a study of glioblastoma patients treated with cediranib vessel normalization was shown by means of MRI as a decrease in vessel diameter and permeability (10). Some studies have shown a correlation between changes in vascular features and patient outcome, but there are some limitations and obstacles that need to be challenged: an understanding of detected characteristics of vasculature with the biology of tumor, also the methodologies require standardization (11).

\section{Resistance to antiangiogenic therapy}

Despite the great success of antiangiogenic therapy, as for anticancer drugs, resistance to antiangiogenic treatment is also an important issue. Introduction of anti-VEGF drugs to anticancer therapy augmented PFS, causing transient disease stabilization, but improvement in OS can not always be achieved. What is more, withdrawal of an antiangiogenic drug from a therapy is followed by rapid regrowth of the tumor. It turned out that some types of cancer can be intrinsically refractory to antiangiogenic therapy or during the treatment acquire resistance to anti-VEGF agents $(103,104)$. The intrinsic resistance may result e.g. from elevated levels of circulating, soluble VEGFR1 (sVEGFR1) before therapy. sVEGFR1 acts as an intrinsic VEGF decoy receptor and thus adding an external anti-VEGF drug has no biological effect. It has been shown that patients with rectal carcinoma, hepatocellular carcinoma, and metastatic colorectal carcinoma who had elevated levels of sVEGFR1 did not benefit from adding bevacizumab to chemotherapy (102). Acquired resistance to antiangiogenic therapy may result from a few possible mechanisms: activation of alternative signaling pathways, recruitment of bone-marrow derived cells, stromal cells of tumor microenvironment, vessel co-option and vessel mimicry and increased invasiveness and metastasis (Fig. 3) (105).

There are a number of other pro-angiogenic pathways and factors that can stimulate blood vessel growth and survival when the VEGF-mediated pathway is inhibited. Some of these pro-angiogenic factors are: angiopoietins (Ang), epidermal growth factor (EGF), fibroblast growth factors (FGF1 and FGF2), hepatocyte growth factor (HGF), interleukin 8 (IL-8), platelet-derived growth factor C (PDGF-C) and placental growth factor (PlGF) $(11,105)$. The upregulation of PlGF, FGF2, IL-8 expression could be observed in colorectal, glioblastoma, renal cell and hepatocellular cancer patients after anti-VEGF therapy (106-109). Proteomic analysis performed in bevacizumab treated breast cancer xenograft showed upregulation of several compensatory signaling pathways with persistent mTOR signaling. It was next hypothesized that targeting the PI3K pathway would increase the efficacy of therapy consisting of bevacizumab and indeed combining an MTOR inhibitor with bevacizumab increased the effectiveness of such treatment. Therefore, exploring the mechanisms activated upon VEGF signaling inhibition and next their attenuation could avoid failure and simultaneously improve the efficacy of therapy (110).

Growth factors released by cancer cells also recruit bone marrow-derived cells into the tumor microenvironment: monocytes/macrophages, endothelial precursor cells (EPCs), myeloid-derived suppressor cells (MDSCs) and cancer-associated fibroblasts (CAFs). These cells contribute to the induction of resistance to antiangiogenic therapy (105). Anti-VEGF agents have been shown to induce the expression of factors such as stromal derived factor-1 (SDF-1), PIGF, stem cell factor (SCF), interleukin 6 (IL-6) and others that are involved in recruitment of bone marrow-derived cells (111). The resistance to sunitinib was correlated in studies of metastatic renal cell carcinoma (mRCC) with infiltration of the tumor tissue with

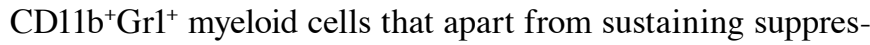
sion of immune cells produce proangiogenic factors (112). A study with the use of an anti-Gr1 antibody and anti-VEGF treatment showed improved tumor growth inhibition compared to anti-VEGF alone and delayed the onset of refractoriness (113). It was found that $\mathrm{CD}_{1} 1^{+} \mathrm{Gr} 1^{+}$cells, upon G-CSF stimulation, 


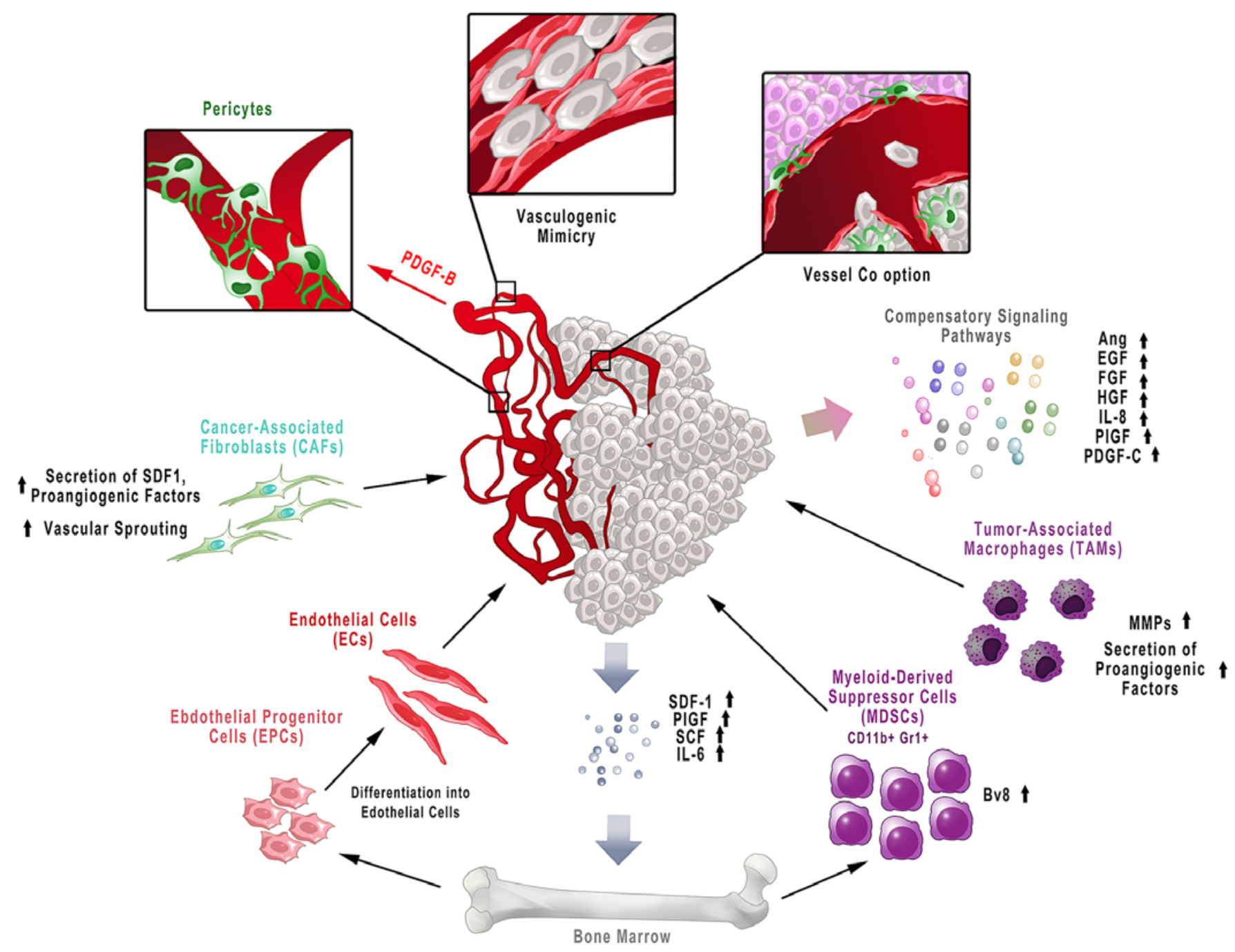

Figure 3. Resistance to antiangiogenic therapy. Acquired resistance to antiangiogenic therapy may result from a few possible mechanisms: cancer cells produce multiple proangiogenic factors and activate alternative signaling pathways other than VEGF/VEGFR, recruit bone-marrow derived cells (MDSCs, EPCs) and stromal cells [cancer-associated fibroblasts (CAFs), pericytes] into tumor microenvironment, or use other than angiogenesis mechanisms such as vessel co-option and vessel mimicry.

express the Bv8 protein, known as prokineticin-2, mediator of VEGF-independent angiogenesis. Blocking Bv8 with neutralizing antibody caused angiogenesis inhibition and tumor growth and together with anti-VEGF antibodies exhibit an additive effect (114). Angiogenesis and the immune system are bidirectionally dependent; therefore, appropriate knowledge of their relationship may help in developing new effective treatment strategies (115). Tumor-associated macrophages (TAMs) contribute to resistance to antiangiogenic therapy by secretion of a number of proangiogenic factors. Moreover, these cells secrete MMPs that degrade extracellular matrix with concomitant release of matrix-sequestered growth factors that contribute to tumor growth and angiogenesis (116).

Tumors are also infiltrated with stromal cells, such as CAFs or pericytes, which are also engaged in resistance to antiangiogenic agents (105). CAFs contribute to tumor angiogenesis through secretion of angiogenic factors, whilst via production of SDF-1 they recruit bone-marrow endothelial progenitor cells (VEGF-independent mechanism) (117). It has also been shown that in tumors resistant to anti-VEGF therapy CAFs expressed pro-angiogenic PDGF-C. Blocking PDGF-C by neutralizing antibodies inhibited angiogenesis and in combination with anti-VEGF antibody revealed an additive effect (118). In turn, pericytes are recruited in response to PDGF-B released by $\mathrm{ECs}$, and are responsible for vessel stabilization and maturation (119). The role of pericytes is to protect ECs from antiangiogenic agents, as well as to inhibit EC proliferation. After the treatment with angiogenesis inhibitors, an increase in pericyte coverage microvessels could be observed (105). On the other hand, enhancing tumor vessel covering by pericytes, the vessel maturation and resultant decreased leakiness may improve chemotherapy delivery. Therefore, the role of pericytes and PDGF-B mediated signaling in resistance to antiangiogenic therapy requires further study (103).

Tumor vascularization may be a result of a few different potential mechanisms. Apart from angiogenesis, cancer may achieve new vasculature by vessel co-option (using existing vessels), vascular mimicry (the process of forming vessels from tumor cells) and vasculogenesis (involving bone marrowderived progenitor cells) (120). For example, in glioblastoma multiforme it was shown that VEGF signaling inhibition caused more invasive tumors and it was proposed that activation of 
MET (the cellular receptor for HGF) after inhibition of VEGF signaling, as well as tumor-derived EC-induced angiogenesis and vasculogenic mimicry, could be engaged in anti-VEGF therapy resistance (121).

New possible mechanisms of tumor escape from antiangiogenic therapy include: EC heterogeneity, antiangiogenic VEGF, extracellular vesicles, lysosomal sequestration, glycosylation-dependent resistance and genetic polymorphism (reviewed in ref. 105).

\section{Conclusion}

The discovery of tumor angiogenesis and the subsequent concept of antiangiogenic therapy was a great breakthrough in anticancer treatment and improved our knowledge of the biology of cancer. In many cases, antiangiogenic agents when added to standard chemotherapy offered an improvement in therapeutic efficacy with different cancers: colorectal, breast, non-small cell lung cancer and hepatocellular carcinoma. However, a decade after approval of the first antiangiogenic agents, today all the above issues and obstacles related to antiangiogenic therapy in solid tumors have to be reconsidered in order to offer appropriate treatment for patients. Combining knowledge of the mechanisms of resistance to antiangiogenic therapy, the relationship between angiogenesis and immunity in cancer, validation of prognostic and predictive biomarkers, and targeting multiple signaling molecules, but with rationally designed schedule, may advance anticancer therapy and offer new promising results in the future.

\section{Acknowledgements}

The present study was supported by a grant from the National Science Center (Preludium 2013/09/N/NZ4/01720) and the Wroclaw Center of Biotechnology program The Leading National Research Center (KNOW) for the years 2014-2018.

\section{References}

1. Folkman J, Bach M, Rowe JW, Davidoff F, Lambert P, Hirsch C, Goldberg A, Hiatt HH, Glass J and Henshaw E: Tumor angiogenesis: Therapeutic implications. N Engl J Med 285: 1182-1186, 1971.

2. Ribatti D: History of research on tumor angiogenesis. Springer, New York, NY, 2009.

3. Senger DR, Galli SJ, Dvorak AM, Perruzzi CA, Harvey VS and Dvorak HF: Tumor cells secrete a vascular permeability factor that promotes accumulation of ascites fluid. Science 219: 983-985, 1983

4. Ferrara N: Vascular endothelial growth factor. Arterioscler Thromb Vasc Biol 29: 789-791, 2009.

5. Gupta K, Kshirsagar S, Li W, Gui L, Ramakrishnan S, Gupta P, Law PY and Hebbel RP: VEGF prevents apoptosis of human microvascular endothelial cells via opposing effects on MAPK/ ERK and SAPK/JNK signaling. Exp Cell Res 247: 495-504, 1999.

6. Cross MJ and Claesson-Welsh L: FGF and VEGF function in angiogenesis: Signalling pathways, biological responses and therapeutic inhibition. Trends Pharmacol Sci 22: 201-207, 2001.

7. Hanahan D and Weinberg RA: Hallmarks of cancer: The next generation. Cell 144: 646-674, 2011.

8. Sennino B, Kuhnert F, Tabruyn SP, Mancuso MR, Hu-Lowe DD, Kuo CJ and McDonald DM: Cellular source and amount of vascular endothelial growth factor and platelet-derived growth factor in tumors determine response to angiogenesis inhibitors. Cancer Res 69: 4527-4536, 2009.
9. Goel S, Duda DG, Xu L, Munn LL, Boucher Y, Fukumura D and Jain RK: Normalization of the vasculature for treatment of cancer and other diseases. Physiol Rev 91: 1071-1121, 2011.

10. Carmeliet P and Jain RK: Principles and mechanisms of vessel normalization for cancer and other angiogenic diseases. Nat Rev Drug Discov 10: 417-427, 2011.

11. Vasudev NS and Reynolds AR: Anti-angiogenic therapy for cancer: Current progress, unresolved questions and future directions. Angiogenesis 17: 471-494, 2014.

12. Jain RK: Antiangiogenesis strategies revisited: From starving tumors to alleviating hypoxia. Cancer Cell 26: 605-622, 2014.

13. McIntyre A and Harris AL: Metabolic and hypoxic adaptation to anti-angiogenic therapy: A target for induced essentiality. EMBO Mol Med 7: 368-379, 2015.

14. Wang Z, Dabrosin C, Yin X, Fuster MM, Arreola A, Rathmell WK, Generali D, Nagaraju GP, El-Rayes B, Ribatti D, et al: Broad targeting of angiogenesis for cancer prevention and therapy. Semin Cancer Biol 35 (Suppl): S224-S243, 2015.

15. Hurwitz H, Fehrenbacher L, Novotny W, Cartwright $T$, Hainsworth J, Heim W, Berlin J, Baron A, Griffing S, Holmgren E, et al: Bevacizumab plus irinotecan, fluorouracil, and leucovorin for metastatic colorectal cancer. N Engl J Med 350: 2335-2342, 2004.

16. Sandler A, Gray R, Perry MC, Brahmer J, Schiller JH, Dowlati A, Lilenbaum R and Johnson DH: Paclitaxel-carboplatin alone or with bevacizumab for non-small-cell lung cancer. N Engl J Med 355: 2542-2550, 2006.

17. Reck M, von Pawel J, Zatloukal P, Ramlau R, Gorbounova V, Hirsh V, Leighl N, Mezger J, Archer V, Moore N, et al: Phase III trial of cisplatin plus gemcitabine with either placebo or bevacizumab as first-line therapy for nonsquamous non-small-cell lung cancer: AVAiL. J Clin Oncol 27: 1227-1234, 2009.

18. Reck M, von Pawel J, Zatloukal P, Ramlau R, Gorbounova V, Hirsh V, Leighl N, Mezger J, Archer V, Moore N, et al; BO17704 Study Group: Overall survival with cisplatin-gemcitabine and bevacizumab or placebo as first-line therapy for nonsquamous non-small-cell lung cancer: Results from a randomised phase III trial (AVAiL). Ann Oncol 21: 1804-1809, 2010.

19. Al-Husein B, Abdalla M, Trepte M, Deremer DL and Somanath PR: Antiangiogenic therapy for cancer: An update. Pharmacotherapy 32: 1095-1111, 2012.

20. Poveda AM, Selle F, Hilpert F, Reuss A, Savarese A, Vergote I, Witteveen P, Bamias A, Scotto N, Mitchell L, et al: Bevacizumab combined with weekly paclitaxel, pegylated liposomal doxorubicin, or topotecan in platinum-resistant recurrent ovarian cancer: Analysis by chemotherapy cohort of the randomized phase III AURELIA trial. J Clin Oncol 33: 3836-3838, 2015.

21. Liu JF and Matulonis UA: Bevacizumab in newly diagnosed ovarian cancer. Lancet Oncol 16: 876-878, 2015.

22. Krill LS and Tewari KS: Integration of bevacizumab with chemotherapy doublets for advanced cervical cancer. Expert Opin Pharmacother 16: 675-683, 2015.

23. Crafton SM and Salani R: Beyond chemotherapy: An overview and review of targeted therapy in cervical cancer. Clin Ther 38: 449-458, 2016

24. Wu P, Nielsen TE and Clausen MH: FDA-approved small-molecule kinase inhibitors. Trends Pharmacol Sci 36: 422-439, 2015.

25. Wu P, Nielsen TE and Clausen MH: Small-molecule kinase inhibitors: An analysis of FDA-approved drugs. Drug Discov Today 21: 5-10, 2016.

26. Ciombor KK and Berlin J: Aflibercept - a decoy VEGF receptor Curr Oncol Rep 16: 368, 2014.

27. Aprile G, Rijavec E, Fontanella C, Rihawi K and Grossi F: Ramucirumab: Preclinical research and clinical development. Onco Targets Ther 7: 1997-2006, 2014.

28. Tiwari P: Ramucirumab: Boon or bane. J Egypt Natl Canc Inst 28: 133-140, 2016

29. (http://www.fda.gov/) Accessed 22 Apr 2016.

30. Calero R, Morchon E, Johnsen JI and Serrano R: Sunitinib suppress neuroblastoma growth through degradation of MYCN and inhibition of angiogenesis. PLoS One 9: e95628, 2014.

31. Maj E, Filip-Psurska B, Świtalska M, Kutner A, Wietrzyk J and Vitamin D: Vitamin D analogs potentiate the antitumor effect of imatinib mesylate in a human A549 lung tumor model. Int J Mol Sci 16: 27191-27207, 2015.

32. Legros L, Bourcier C, Jacquel A, Mahon FX, Cassuto JP, Auberger P and Pagès G: Imatinib mesylate (STI571) decreases the vascular endothelial growth factor plasma concentration in patients with chronic myeloid leukemia. Blood 104: 495-501, 2004. 
33. Kerbel RS, Viloria-Petit A, Klement G and Rak J: 'Accidental' anti-angiogenic drugs: anti-oncogene directed signal transduction inhibitors and conventional chemotherapeutic agents as examples. Eur J Cancer 36: 1248-1257, 2000.

34. Klement G, Baruchel S, Rak J, Man S, Clark K, Hicklin DJ, Bohlen P and Kerbel RS: Continuous low-dose therapy with vinblastine and VEGF receptor-2 antibody induces sustained tumor regression without overt toxicity. J Clin Invest 105 R15-R24, 2000.

35. Man S, Bocci G, Francia G, Green SK, Jothy S, Hanahan D, Bohlen P, Hicklin DJ, Bergers G and Kerbel RS: Antitumor effects in mice of low-dose (metronomic) cyclophosphamide administered continuously through the drinking water. Cancer Res 62: 2731-2735, 2002

36. Wu H, Xin Y,Zhao J, Sun D, Li W, Hu Y and Wang S: Metronomic docetaxel chemotherapy inhibits angiogenesis and tumor growth in a gastric cancer model. Cancer Chemother Pharmacol 68: 879-887, 2011.

37. Guo XL, Lin GJ, Zhao H, Gao Y, Qian LP, Xu SR, Fu LN, Xu Q and Wang JJ: Inhibitory effects of docetaxel on expression of VEGF, bFGF and MMPs of LS174T cell. World J Gastroenterol 9: 1995-1998, 2003.

38. Blazejczyk A, Papiernik D, Porshneva K, Sadowska J and Wietrzyk J: Endothelium and cancer metastasis: Perspectives for antimetastatic therapy. Pharmacol Rep 67: 711-718, 2015

39. Sagar SM, Yance D and Wong RK: Natural health products that inhibit angiogenesis: A potential source for investigational new agents to treat cancer-Part 1. Curr Oncol 13: 14-26, 2006.

40. Sagar SM, Yance D and Wong RK: Natural health products that inhibit angiogenesis: A potential source for investigational new agents to treat cancer-Part 2. Curr Oncol 13: 99-107, 2006.

41. Sulaiman RS, Basavarajappa HD and Corson TW: Natural product inhibitors of ocular angiogenesis. Exp Eye Res 129: 161-171, 2014.

42. Singh M, Singh P and Shukla Y: New strategies in cancer chemoprevention by phytochemicals. Front Biosci (Elite Ed) 4 $426-452,2012$

43. Kang X, Jin S and Zhang Q: Antitumor and antiangiogenic activity of soy phytoestrogen on 7,12-dimethylbenz[alpha] anthracene-induced mammary tumors following ovariectomy in Sprague-Dawley rats. J Food Sci 74: H237-H242, 2009.

44. Uifălean A, Schneider S, Ionescu C, Lalk M and Iuga CA: Soy isoflavones and breast cancer cell lines: molecular mechanisms and future perspectives. Molecules 21: E13, 2015.

45. Wietrzyk J, Opolski A, Madej J and Radzikowski C: Antitumour and antimetastatic effect of genistein alone or combined with cyclophosphamide in mice transplanted with various tumours depends on the route of tumour transplantation. In Vivo 14: $357-362,2000$

46. Wietrzyk J, Opolski A, Madej J and Radzikowski C: The antitumor effect of postoperative treatment with genistein alone or combined with cyclophosphamide in mice bearing transplantable tumors. Acta Pol Pharm 57 (Suppl): 5-8, 2000.

47. Wietrzyk J, Boratynski J, Grynkiewicz G, Ryczynski A, Radzikowski C and Opolski A: Antiangiogenic and antitumour effects in vivo of genistein applied alone or combined with cyclophosphamide. Anticancer Res 21: 3893-3896, 2001.

48. Park SY, Jeong KJ, Lee J, Yoon DS, Choi WS, Kim YK, Han JW, Kim YM, Kim BK and Lee HY: Hypoxia enhances LPA-induced HIF-1alpha and VEGF expression: Their inhibition by resveratrol. Cancer Lett 258: 63-69, 2007.

49. Yu H, Pan C, Zhao S, Wang Z, Zhang H and Wu W: Resveratrol inhibits tumor necrosis factor-alpha-mediated matrix metalloproteinase- 9 expression and invasion of human hepatocellular carcinoma cells. Biomed Pharmacother 62: 366-372, 2008.

50. Ma Y, Johnson CS and Trump DL: Mechanistic insights of Vitamin D anticancer effects. Vitam Horm 100: 395-431, 2016.

51. Jäpelt RB and Jakobsen J: Vitamin D in plants: A review of occurrence, analysis, and biosynthesis. Front Plant Sci 4: 136, 2013.

52. Haussler MR, Jurutka PW, Mizwicki M and Norman AW: Vitamin $D$ receptor (VDR)-mediated actions of $1 \alpha, 25(\mathrm{OH})_{2}$ vitamin $\mathrm{D}_{3}$ : Genomic and non-genomic mechanisms. Best Pract Res Clin Endocrinol Metab 25: 543-559, 2011.

53. Feldman D, Krishnan AV, Swami S, Giovannucci E and Feldman BJ: The role of vitamin D in reducing cancer risk and progression. Nat Rev Cancer 14: 342-357, 2014.

54. Oikawa T, Hirotani K, Ogasawara H, Katayama T, Nakamura O, Iwaguchi T and Hiragun A: Inhibition of angiogenesis by vitamin D3 analogues. Eur J Pharmacol 178: 247-250, 1990.
55. Bao BY, Yao J and Lee YF: 1alpha, 25-dihydroxyvitamin D3 suppresses interleukin-8-mediated prostate cancer cell angiogenesis. Carcinogenesis 27: 1883-1893, 2006.

56. Ben-Shoshan M, Amir S, Dang DT, Dang LH, Weisman Y and Mabjeesh NJ: 1alpha,25-dihydroxyvitamin $\mathrm{D}_{3}$ (Calcitriol) inhibits hypoxia-inducible factor-1/vascular endothelial growth factor pathway in human cancer cells. Mol Cancer Ther 6: 1433-1439, 2007

57. Chung I, Han G, Seshadri M, Gillard BM, Yu WD, Foster BA, Trump DL and Johnson CS: Role of vitamin D receptor in the antiproliferative effects of calcitriol in tumor-derived endothelial cells and tumor angiogenesis in vivo. Cancer Res 69: 967-975, 2009.

58. Iseki K, Tatsuta M, Uehara H, Iishi H, Yano H, Sakai N and Ishiguro S: Inhibition of angiogenesis as a mechanism for inhibition by lalpha-hydroxyvitamin D3 and 1,25-dihydroxyvitamin D3 of colon carcinogenesis induced by azoxymethane in Wistar rats. Int J Cancer 81: 730-733, 1999.

59. Nakagawa K, Sasaki Y, Kato S, Kubodera N and Okano T: 22-Oxa-1alpha,25-dihydroxyvitamin $\mathrm{D}_{3}$ inhibits metastasis and angiogenesis in lung cancer. Carcinogenesis 26: 1044-1054, 2005.

60. Wietrzyk J, Filip B, Milczarek M, Klopotowska D Maciejewska M, Dabrowska K, Kurzepa A, Dzimira S, Madej $J$ and Kutner A: The influence of 1,25-dihydroxyvitamin $D_{3}$ and 1,24-dihydroxyvitamin $\mathrm{D}_{3}$ on $\alpha_{5} \beta_{3}$ integrin expression in cancer cell lines. Oncol Rep 20: 941-952, 2008.

61. Jones G, Strugnell SA and DeLuca HF: Current understanding of the molecular actions of vitamin D. Physiol Rev 78: 1193-1231, 1998.

62. Ma Y, Trump DL and Johnson CS: Vitamin D in combination cancer treatment. J Cancer 1: 101-107, 2010.

63. Leyssens C, Verlinden L and Verstuyf A: The future of vitamin D analogs. Front Physiol 5: 122, 2014.

64. Milczarek M, Psurski M, Kutner A and Wietrzyk J: Vitamin D analogs enhance the anticancer activity of 5-fluorouracil in an in vivo mouse colon cancer model. BMC Cancer 13: 294, 2013.

65. Milczarek M, Filip-Psurska B, Swietnicki W, Kutner A and Wietrzyk J: Vitamin D analogs combined with 5-fluorouracil in human HT-29 colon cancer treatment. Oncol Rep 32: 491-504, 2014.

66. Okamoto R, Delansorne R, Wakimoto N, Doan NB, Akagi T, Shen M, Ho QH, Said JW and Koeffler HP: Inecalcitol, an analog of $1 \alpha, 25(\mathrm{OH})_{2} \mathrm{D}_{3}$, induces growth arrest of androgen-dependent prostate cancer cells. Int J Cancer 130: 2464-2473, 2012.

67. Protiva P, Pendyala S, Nelson C, Augenlicht LH, Lipkin M and Holt PR: Calcium and 1,25-dihydroxyvitamin D3 modulate genes of immune and inflammatory pathways in the human colon: A human crossover trial. Am J Clin Nutr 103: 1224-1231, 2016.

68. Lappe JM, Travers-Gustafson D, Davies KM, Recker RR and Heaney RP: Vitamin D and calcium supplementation reduces cancer risk: Results of a randomized trial. Am J Clin Nutr 85: 1586-1591, 2007.

69. Jacot W, Firmin N, Roca L, Topart D, Gallet S, Durigova A, Mirr S, Abach L, Pouderoux S, D'Hondt V, et al: Impact of a tailored oral vitamin $\mathrm{D}$ supplementation regimen on serum 25-hydroxyvitamin D levels in early breast cancer patients: A randomized phase III study. Ann Oncol 27: 1235-1241, 2016.

70. Bjelakovic G, Gluud LL, Nikolova D, Whitfield K, Krstic G, Wetterslev J and Gluud C: Vitamin D supplementation for prevention of cancer in adults. Cochrane Database Syst Rev (6): CD007469, 2014.

71. Crew KD: Vitamin D: Are we ready to supplement for breast cancer prevention and treatment? ISRN Oncology 2013, 2013. Article ID 483687. 10.1155/2013/483687.

72. Kim KJ, Li B, Winer J, Armanini M, Gillett N, Phillips HS and Ferrara N: Inhibition of vascular endothelial growth factorinduced angiogenesis suppresses tumour growth in vivo. Nature 362: 841-844, 1993.

73. Jain RK, Duda DG, Clark JW and Loeffler JS: Lessons from phase III clinical trials on anti-VEGF therapy for cancer. Nat Clin Pract Oncol 3: 24-40, 2006.

74. Jayson GC, Hicklin DJ and Ellis LM: Antiangiogenic therapy-evolving view based on clinical trial results. Nat Rev Clin Oncol 9: 297-303, 2012

75. Jain RK: Normalizing tumor vasculature with anti-angiogenic therapy: A new paradigm for combination therapy. Nat Med 7: 987-989, 2001.

76. Jain RK: Normalization of tumor vasculature: An emerging concept in antiangiogenic therapy. Science 307: 58-62, 2005. 
77. Yuan F, Chen Y, Dellian M, Safabakhsh N, Ferrara N and Jain RK: Time-dependent vascular regression and permeability changes in established human tumor xenografts induced by an anti-vascular endothelial growth factor/vascular permeability factor antibody. Proc Natl Acad Sci USA 93: 14765-14770, 1996

78. Dickson PV, Hamner JB, Sims TL, Fraga CH, Ng CYC Rajasekeran S, Hagedorn NL, McCarville MB, Stewart CF and Davidoff AM: Bevacizumab-induced transient remodeling of the vasculature in neuroblastoma xenografts results in improved delivery and efficacy of systemically administered chemotherapy. Clin Cancer Res 13: 3942-3950, 2007.

79. Myers AL, Williams RF, Ng CY, Hartwich JE and Davidoff AM: Bevacizumab-induced tumor vessel remodeling in rhabdomyosarcoma xenografts increases the effectiveness of adjuvant ionizing radiation. J Pediatr Surg 45: 1080-1085, 2010.

80. Inai T, Mancuso M, Hashizume H, Baffert F, Haskell A, Baluk P, Hu-Lowe DD, Shalinsky DR, Thurston G, Yancopoulos GD et al: Inhibition of vascular endothelial growth factor (VEGF) signaling in cancer causes loss of endothelial fenestrations, regression of tumor vessels, and appearance of basement membrane ghosts. Am J Pathol 165: 35-52, 2004.

81. Zhou Q, Guo P and Gallo JM: Impact of angiogenesis inhibition by sunitinib on tumor distribution of temozolomide. Clin Cancer Res 14: 1540-1549, 2008

82. Zhou Q and Gallo JM: Differential effect of sunitinib on the distribution of temozolomide in an orthotopic glioma model. Neuro Oncol 11: 301-310, 2009.

83. Willett CG, Boucher Y, di Tomaso E, Duda DG, Munn LL, Tong RT, Chung DC, Sahani DV, Kalva SP, Kozin SV, et al: Direct evidence that the VEGF-specific antibody bevacizumab has antivascular effects in human rectal cancer. Nat Med 10: 145-147, 2004.

84. Shi S, Chen L and Huang G: Antiangiogenic therapy improves the antitumor effect of adoptive cell immunotherapy by normalizing tumor vasculature. Med Oncol 30: 698, 2013.

85. Huang Y, Yuan J, Righi E, Kamoun WS, Ancukiewicz M, Nezivar J, Santosuosso M, Martin JD, Martin MR, Vianello F, et al: Vascular normalizing doses of antiangiogenic treatment reprogram the immunosuppressive tumor microenvironment and enhance immunotherapy. Proc Natl Acad Sci USA 109 17561-17566, 2012

86. Mancuso MR, Davis R, Norberg SM, O'Brien S, Sennino B Nakahara T, Yao VJ, Inai T, Brooks P, Freimark B, et al: Rapid vascular regrowth in tumors after reversal of VEGF inhibition. J Clin Invest 116: 2610-2621, 2006.

87. Griffioen AW, Mans LA, de Graaf AMA, Nowak-Sliwinska P, de Hoog CL, de Jong TAM, Vyth-Dreese FA, van Beijnum JR, Bex A and Jonasch E: Rapid angiogenesis onset after discontinuation of sunitinib treatment of renal cell carcinoma patients. Clin Cancer Res 18: 3961-3971, 2012.

88. Wolter P, Beuselinck B, Pans S and Schöffski P: Flare-up: An often unreported phenomenon nevertheless familiar to oncologists prescribing tyrosine kinase inhibitors. Acta Oncol 48 : 621-624, 2009.

89. Chen DR, Lin C and Wang YF: Window of opportunity: A new insight into sequential bevacizumab and paclitaxel in two cases of metastatic triple-negative breast cancer. Exp Ther Med 10: 885-888, 2015

90. Lee CG, Heijn M, di Tomaso E, Griffon-Etienne G, Ancukiewicz M, Koike C, Park KR, Ferrara N, Jain RK, Suit HD, et al: Anti-Vascular endothelial growth factor treatment augments tumor radiation response under normoxic or hypoxic conditions. Cancer Res 60: 5565-5570, 2000.

91. Zhang L, Takara K, Yamakawa D, Kidoya H and Takakura N Apelin as a marker for monitoring the tumor vessel normalization window during antiangiogenic therapy. Cancer Sci 107: 36-44, 2016

92. McGee MC, Hamner JB, Williams RF, Rosati SF, Sims TL, $\mathrm{Ng}$ CY, Gaber MW, Calabrese C, Wu J, Nathwani AC, et al: Improved intratumoral oxygenation through vascular normalization increases glioma sensitivity to ionizing radiation. Int J Radiat Oncol Biol Phys 76: 1537-1545, 2010.

93. Dings RPM, Loren M, Heun H, McNiel E, Griffioen AW, Mayo KH and Griffin RJ: Scheduling of radiation with angiogenesis inhibitors anginex and Avastin improves therapeutic outcome via vessel normalization. Clin Cancer Res 13: 3395-3402, 2007.

94. Vangestel C, Van de Wiele C, Van Damme N, Staelens S, Pauwels P, Reutelingsperger CPM and Peeters M: ${ }^{99 \mathrm{~m}} \mathrm{Tc}-(\mathrm{CO})$ His-annexin A5 micro-SPECT demonstrates increased cell death by irinotecan during the vascular normalization window caused by bevacizumab. J Nucl Med 52: 1786-1794, 2011.
95. Hernandez-Agudo E, Mondejar T, Soto-Montenegro ML, Megias D, Mouron S, Sanchez J, Hidalgo M, LopezCasas PP, Mulero F, Desco M, et al: Monitoring vascular normalization induced by antiangiogenic treatment with F-fluoromisonidazole-PET. Mol Oncol 10: 704-718, 2015.

96. Cao Y: Off-tumor target--beneficial site for antiangiogenic cancer therapy? Nat Rev Clin Oncol 7: 604-608, 2010.

97. Yang Y, Zhang Y, Cao Z, Ji H, Yang X, Iwamoto H, Wahlberg E, Länne T, Sun B and Cao Y: Anti-VEGF- and anti-VEGF receptor-induced vascular alteration in mouse healthy tissues. Proc Natl Acad Sci USA 110: 12018-12023, 2013

98. Wong AK, Alfert M, Castrillon DH, Shen Q, Holash J, Yancopoulos GD and Chin L: Excessive tumor-elaborated VEGF and its neutralization define a lethal paraneoplastic syndrome. Proc Natl Acad Sci USA 98: 7481-7486, 2001.

99. Pelosof LC and Gerber DE: Paraneoplastic syndromes: An approach to diagnosis and treatment. Mayo Clin Proc 85: 838-854, 2010

100. Xue Y, Religa P, Cao R, Hansen AJ, Lucchini F, Jones B, Wu Y, Zhu Z, Pytowski B, Liang Y, et al: Anti-VEGF agents confer survival advantages to tumor-bearing mice by improving cancer-associated systemic syndrome. Proc Natl Acad Sci USA 105: 18513-18518, 2008.

101. Cao Y: Future options of anti-angiogenic cancer therapy. Chin J Cancer 35: 21, 2016.

102. Jain RK: Normalizing tumor microenvironment to treat cancer: Bench to bedside to biomarkers. J Clin Oncol 31: 2205-2218, 2013.

103. Loges S, Schmidt T and Carmeliet P: Mechanisms of resistance to anti-angiogenic therapy and development of third-generation anti-angiogenic drug candidates. Genes Cancer 1: 12-25, 2010.

104. Bergers G and Hanahan D: Modes of resistance to anti-angiogenic therapy. Nat Rev Cancer 8: 592-603, 2008.

105. van Beijnum JR, Nowak-Sliwinska P, Huijbers EJM, Thijssen VL and Griffioen AW: The great escape; the hallmarks of resistance to antiangiogenic therapy. Pharmacol Rev 67: 441-461, 2015.

106. Willett CG, Boucher Y, Duda DG, di Tomaso E, Munn LL, Tong RT, Kozin SV, Petit L, Jain RK, Chung DC, et al: Surrogate markers for antiangiogenic therapy and dose-limiting toxicities for bevacizumab with radiation and chemotherapy: Continued experience of a phase I trial in rectal cancer patients. J Clin Oncol 23: 8136-8139, 2005.

107. Kopetz S, Hoff PM, Morris JS, Wolff RA, Eng C, Glover KY, Adinin R, Overman MJ, Valero V, Wen S, et al: Phase II trial of infusional fluorouracil, irinotecan, and bevacizumab for metastatic colorectal cancer: Efficacy and circulating angiogenic biomarkers associated with therapeutic resistance. J Clin Oncol 28: 453-459, 2010

108. Huang D, Ding Y, Zhou M, Rini BI, Petillo D, Qian CN, Kahnoski R, Futreal PA, Furge KA and Teh BT: Interleukin-8 mediates resistance to antiangiogenic agent sunitinib in renal cell carcinoma. Cancer Res 70: 1063-1071, 2010.

109. Batchelor TT, Sorensen AG, di Tomaso E, Zhang WT, Duda DG, Cohen KS, Kozak KR, Cahill DP, Chen PJ, Zhu M, et al: AZD2171, a pan-VEGF receptor tyrosine kinase inhibitor, normalizes tumor vasculature and alleviates edema in glioblastoma patients. Cancer Cell 11: 83-95, 2007.

110. Lindholm EM, Krohn M, Iadevaia S, Kristian A, Mills GB Mælandsmo GM and Engebraaten O: Proteomic characterization of breast cancer xenografts identifies early and late bevacizumab-induced responses and predicts effective drug combinations. Clin Cancer Res 20: 404-412, 2014

111. Ebos JML, Lee CR, Christensen JG, Mutsaers AJ and Kerbel RS: Multiple circulating proangiogenic factors induced by sunitinib malate are tumor-independent and correlate with antitumor efficacy. Proc Natl Acad Sci USA 104: 17069-17074, 2007.

112. Finke J, Ko J, Rini B, Rayman P, Ireland J and Cohen P: MDSC as a mechanism of tumor escape from sunitinib mediated antiangiogenic therapy. Int Immunopharmacol 11: 856-861, 2011.

113. Shojaei F, Wu X, Malik AK, Zhong C, Baldwin ME, Schanz S, Fuh G, Gerber HP and Ferrara N: Tumor refractoriness to anti-VEGF treatment is mediated by $\mathrm{CD} 11 \mathrm{~b}^{+} \mathrm{Grl}^{+}$myeloid cells. Nat Biotechnol 25: 911-920, 2007.

114. Shojaei F, Wu X, Zhong C, Yu L, Liang XH, Yao J, Blanchard D, Bais C, Peale FV, van Bruggen N, et al: Bv8 regulates myeloidcell-dependent tumour angiogenesis. Nature 450: 825-831, 2007.

115. Tartour E, Pere H, Maillere B, Terme M, Merillon N, Taieb J, Sandoval F, Quintin-Colonna F, Lacerda K, Karadimou A, et al: Angiogenesis and immunity: A bidirectional link potentially relevant for the monitoring of antiangiogenic therapy and the development of novel therapeutic combination with immunotherapy. Cancer Metastasis Rev 30: 83-95, 2011. 
116. Mantovani A, Biswas SK, Galdiero MR, Sica A and Locati M Macrophage plasticity and polarization in tissue repair and remodelling. J Pathol 229: 176-185, 2013.

117. Orimo A, Gupta PB, Sgroi DC, Arenzana-Seisdedos F Delaunay 0T, Naeem R, Carey VJ, Richardson AL and Weinberg RA: Stromal fibroblasts present in invasive human breast carcinomas promote tumor growth and angiogenesis through elevated SDF-1/CXCL12 secretion. Cell 121: 335-348, 2005.

118. Crawford Y, Kasman I, Yu L, Zhong C, Wu X, Modrusan Z Kaminker $\mathrm{J}$ and Ferrara N: PDGF-C mediates the angiogenic and tumorigenic properties of fibroblasts associated with tumors refractory to anti-VEGF treatment. Cancer Cell 15: 21-34, 2009.
119. Gerhardt $\mathrm{H}$ and Betsholtz C: Endothelial-pericyte interactions in angiogenesis. Cell Tissue Res 314: 15-23, 2003.

120. Welti J, Loges S, Dimmeler S and Carmeliet P: Recent molecular discoveries in angiogenesis and antiangiogenic therapies in cancer. J Clin Invest 123: 3190-3200, 2013.

121. Soda Y, Myskiw C, Rommel A and Verma IM: Mechanisms of neovascularization and resistance to anti-angiogenic therapies in glioblastoma multiforme. J Mol Med (Berl) 91: 439-448, 2013. 